\title{
Measuring the impact of sea surface temperature on the human incidence of Vibrio sp. infection in British Columbia, Canada, 1992-2017
}

\author{
Eleni Galanis ${ }^{1,2^{*}}$, Michael Otterstatter ${ }^{1,2}$ and Marsha Taylor ${ }^{1}$
}

\begin{abstract}
Background: Vibrio growth in the environment is related to sea surface temperature (SST). The incidence of human Vibrio illness increased sharply in British Columbia (BC) between 2008 and 2015 for unknown reasons, culminating in the largest outbreak of shellfish-associated Vibrio parahaemolyticus (Vp) in Canadian history in 2015. Our objective was to assess the relationship between SST and Vibrio illness in BC, Canada during 1992-2017 and assess the role of SST and other environmental factors in the 2015 Vp outbreak.

Methods: Cases of Vibrio infection reported to the BC Centre for Disease Control during 1992-2017 were used. SST data were obtained from NOAA and NASA. We assessed changes in incidence trend of annual Vibrio cases during 1992-2017 using a Poisson regression. We assessed the correlation between annual Vibrio cases and the average annual maximum SST using a Spearman rank-order correlation. We modeled the association between weekly Vp case counts, SST and other environmental factors during 2007-2017 using a Poisson regression.

Results: There was a significant increase in Vibrio cases between 2008 and 2015 (annual slope $=0.163, P<0.001$ ). Increased Vibrio incidence was observed in most El Niño years. There was a significant correlation between annual Vibrio cases and maximum SST from 1992 to $2017(r=0.46, P=0.018)$. Our model captured observed seasonal variation in shellfish-associated Vp in most years, but underestimated the 2015 Vp outbreak.

Conclusions: Vibrio incidence has been increasing concurrently with increasing SST in BC during 2008-2015. The 2015 Vp outbreak was not fully explained by climatic factors and may in part have been associated with other factors. Vp subtyping would be useful in the future to understand the combined effects of SST changes and strain emergence.
\end{abstract}

Keywords: Vibrio, Vibrio parahaemolyticus, Sea surface temperature, Epidemiology, Climate change

\footnotetext{
* Correspondence: Eleni.galanis@bccdc.ca

${ }^{1}$ British Columbia Centre for Disease Control, 655 W 12th Ave, Vancouver, British Columbia V5Z 4R4, Canada

${ }^{2}$ School of Population and Public Health, University of British Columbia,

Vancouver, British Columbia, Canada
}

C The Author(s). 2020 Open Access This article is licensed under a Creative Commons Attribution 4.0 International License, which permits use, sharing, adaptation, distribution and reproduction in any medium or format, as long as you give appropriate credit to the original author(s) and the source, provide a link to the Creative Commons licence, and indicate if changes were made. The images or other third party material in this article are included in the article's Creative Commons licence, unless indicated otherwise in a credit line to the material. If material is not included in the article's Creative Commons licence and your intended use is not permitted by statutory regulation or exceeds the permitted use, you will need to obtain permission directly from the copyright holder. To view a copy of this licence, visit http://creativecommons.org/licenses/by/4.0/ The Creative Commons Public Domain Dedication waiver (http://creativecommons.org/publicdomain/zero/1.0/) applies to the data made available in this article, unless otherwise stated in a credit line to the data. 


\section{Background}

Vibrio parahaemolyticus ( $\mathrm{Vp}$ ) is a naturally-occurring bacterium in ocean water worldwide [1]. If ingested, Vp can lead to diarrhea, vomiting, nausea and fever lasting 1-7 days and, rarely, death. The majority of $\mathrm{Vp}$ infections are caused by the consumption of raw oysters [1]. Other exposures include the inadvertent swallowing of, or exposure of wounds or external ears to, ocean water.

Sea surface temperature (SST) is thought to be the most important environmental predictor of $\mathrm{Vp}$, with higher temperature leading to higher $\mathrm{Vp}$ concentration [2-4]. In British Columbia (BC), Canada, SST was found to be significantly associated with $\mathrm{Vp}$ in oysters and with human Vp illness [5]. The vast majority of these Vp infections occurred during the summer months, following the consumption of raw BC oysters [6]. Warm air temperature may also contribute to $\mathrm{Vp}$ multiplication in oyster meat post-harvest [7].

The incidence of human Vp illness increased sharply in BC between 2009 and 2015 for unknown reasons [8]. In the summer of 2015, Canada experienced the largest outbreak of $\mathrm{Vp}$ cases ever reported and the first outbreak associated with consumption of raw BC oysters since 1997 [9, 10]. Eighty-two people were infected with $\mathrm{Vp}$ across the country and 66 (80\%) consumed commercially-harvested raw BC oysters. Given that for every case of Vp reported, 92 additional cases are estimated to have occurred in the community, this outbreak may have affected over 7500 Canadians [11]. Sea surface temperature, which was above historical levels at the time, may have played an important role in the outbreak [9]. Following the 2015 outbreak, annual Vp incidence in $\mathrm{BC}$ dropped dramatically, returning to levels observed prior to 2009 [8].

The objective of this paper is to analyze the historical relationship between temperature and $\mathrm{Vp}$ human incidence in BC and assess its role in the 2015 Vp outbreak.

\section{Methods}

We conducted two analyses: the first was to assess the long-term trends and correlation between annual SST and Vibrio illnesses in BC during 1992-2017; the second was to model the association between weekly $\mathrm{Vp}$ case counts, temperature and other environmental factors that may have played a role in the 2015 outbreak and subsequent decline in $\mathrm{Vp}$ incidence.

\section{Data}

Vibrio infection is a reportable disease in $\mathrm{BC}$; a case is defined as a resident of $\mathrm{BC}$ with Vibrio isolated from stool. BC regional health authority staff interview cases using a standard form to identify the source of illness [12]. The vast majority of Vibrio infections in $\mathrm{BC}$ are caused by Vp (in 2011-2017, Vp comprised $87.0 \%$ of all Vibrio infections) [6].

Cases of Vp infection from 2007 to 2017, and cases of all Vibrio infection from 1992 to 2017, were extracted from the $\mathrm{BC}$ Centre for Disease Control public health information system (Vp specific incidence could not be calculated in early years). Annual incidence rates were calculated using the BC population from BC Stats (www2.gov.bc.ca/gov/content/data/statistics). Weekly numbers of $\mathrm{Vp}$ cases where the source of illness was the consumption of shellfish (including all types, raw and cooked, commercial and self-harvested) were used for the regression model.

The study area was the Strait of Georgia, an arm of the Pacific Ocean separating Vancouver Island and the lower mainland of BC, as described elsewhere [5]. To examine long-term trends, historical SST data for 1992 to 2014 were obtained from the National Oceanic and Atmospheric Administration (NOAA) Optimum Interpolation Sea Surface Temperature (OISST) (https://www.ncdc. noaa.gov/oisst). Average annual maximum SST values were calculated from maximum yearly values recorded at three representative points in the study area (Strait of Georgia, 49 $52^{\prime} 30.0^{\prime \prime} \mathrm{N} 124^{\circ} 52^{\prime} 30.0^{\prime \prime} \mathrm{W}$; west coast of Vancouver Island, $48^{\circ} 22^{\prime} 30.0^{\prime \prime} \mathrm{N} 125^{\circ} 22^{\prime} 30.0^{\prime \prime} \mathrm{W}$; east coast of Vancouver Island, $48^{\circ} 52^{\prime} 30.0^{\prime \prime} \mathrm{N} 123^{\circ} 07^{\prime} 30.0^{\prime \prime} \mathrm{W}$ ) and compared against annual counts of all Vibrio cases reported in BC during 1992-2017.

For the regression model, SST data for 2007 to 2017 were obtained from the National Aeronautics and Space Administration (NASA) satellite-based Multiscale Ultrahigh Resolution (MUR) product (https://podaac.jpl.nasa.gov/ Multi-scale_Ultra-high_Resolution_MUR-SST) [5]. Daily SST values were averaged across all landfile (oyster harvest site) coordinates in the study area and then averaged weekly for April through October 2007-2017. Given that SST values were similar across landfiles (standard deviation of weekly SST $=1.1^{\circ} \mathrm{C}$ on average, with a maximum of $2.9^{\circ} \mathrm{C}$ ), the average weekly value for the study area was used [5]. From these data, annual maximum and minimum SST values were calculated. Daily air temperature data for 2007 to 2017 were obtained (http://climate. weather.gc.ca/). Daily maximum air temperature values from the centrally located Comox A weather station $\left(49^{\circ} 43^{\prime} 00^{\prime \prime} \mathrm{N}, 124^{\circ} 54^{\prime} 00^{\prime \prime} \mathrm{W}\right)$ were summarized as weekly average maximum values.

Annual live oyster production data in dozens were obtained from the Department of Fisheries and Oceans for 2011-2016 and from the BC Ministry of Agriculture for 2007-2010. Monthly live oyster export data in kilograms for 2007-2016 were obtained from the BC Ministry of Agriculture (source: Statistics Canada, CATSNETAnalytics, 2017). These were converted into dozens using dozens $=$ kg*2.2046/4.5 (BC Ministry of Agriculture 2017). 
The mean ( \pm standard deviation) time between shellfish harvest and the report of an associated $\mathrm{Vp}$ case was 17 days (IQR $=8$ days) [5]. Lagged SST and air temperature values for 1, 2 and 3 weeks prior to the week of case report were generated. Previous work in BC has shown that $\mathrm{Vp}$ cases are associated with SST values above $14{ }^{\circ} \mathrm{C}$ [5]. Therefore, for each year, the first week with mean SST above $14{ }^{\circ} \mathrm{C}$ was identified and the cumulative weekly mean SST for each year beginning January 1 and beginning with the first week above $14^{\circ} \mathrm{C}$ was calculated.

\section{Analysis}

Significant changes in incidence trend were assessed using a Poisson regression of annual Vibrio cases during 1992-2017 fitted using the Joinpoint software [13]. The correlation between annual Vibrio cases and average annual maximum SST, and the correlation between weekly Vp cases and average weekly SST, and SST anomaly (current week SST - average SST for that week during previous 3 years), were assessed using a Spearman rankorder correlation.

To model the association between $\mathrm{Vp}$ cases, temperature and other factors, $\mathrm{Vp}$ case counts for calendar weeks 22-41 (summer period) during 2007-2017 were used. Poisson regressions of weekly shellfish associated $\mathrm{Vp}$ cases were developed, including the following predictors: weekly mean SST and maximum air temperature at 1-, 2- and 3-week lags, first week of the year with SST above $14{ }^{\circ} \mathrm{C}$, yearly cumulative SST, annual minimum and maximum SST, annual oyster production volume, and monthly oyster export volume. The fit of models with differing combinations of predictors were compared using the AIC goodness-of-fit statistic.
Given the modest sample size for this analysis, we focused on main effects and did not consider two-way or higher order interaction terms. Preliminary modeling showed that oyster availability did not explain variation in Vp counts; hence, annual production and monthly export volumes were excluded from further analysis. We found that weekly SST was a stronger correlate (Spearman correlation: $r=0.44, P<0.01)$ of $\mathrm{Vp}$ counts than weekly SST anomaly (Spearman correlation: $r=0.10$, $P=0.15$ ), so only the former was included in our model. We examined other water quality measures (e.g., dissolved oxygen, salinity), but these were not consistently available across our study period.

The best fit model (smallest AIC value) included SST at 1 and 3 week lags from the week of case report, air temperature for lags of 1,2 and 3 weeks, the cumulative SST for weeks 1-14, and the annual minimum SST.

\section{Results}

No consistent trend in the annual number of reported Vibrio cases was detected during 1992-2007 (annual slope $=-0.008, P=0.897$ ) (Fig. 1). After 2007, the number of cases increased every year to a peak of 93 cases in $2015(2008-2015$ annual slope $=0.163 P<0.001)$. After the outbreak year, numbers dropped to 37 cases in 2016 and 51 in 2017. The change in slope was not significant given the small sample size $(2015-2017$ annual slope $=$ $-0.347, P=0.235)$. The annual number of Vibrio cases closely followed the average maximum SST (Fig. 1). Every peak in Vibrio cases occurred during or near to a period of elevated SST, corresponding to years with moderate to strong El Niño events. The long term increase in SST observed during 2008-2015 coincided

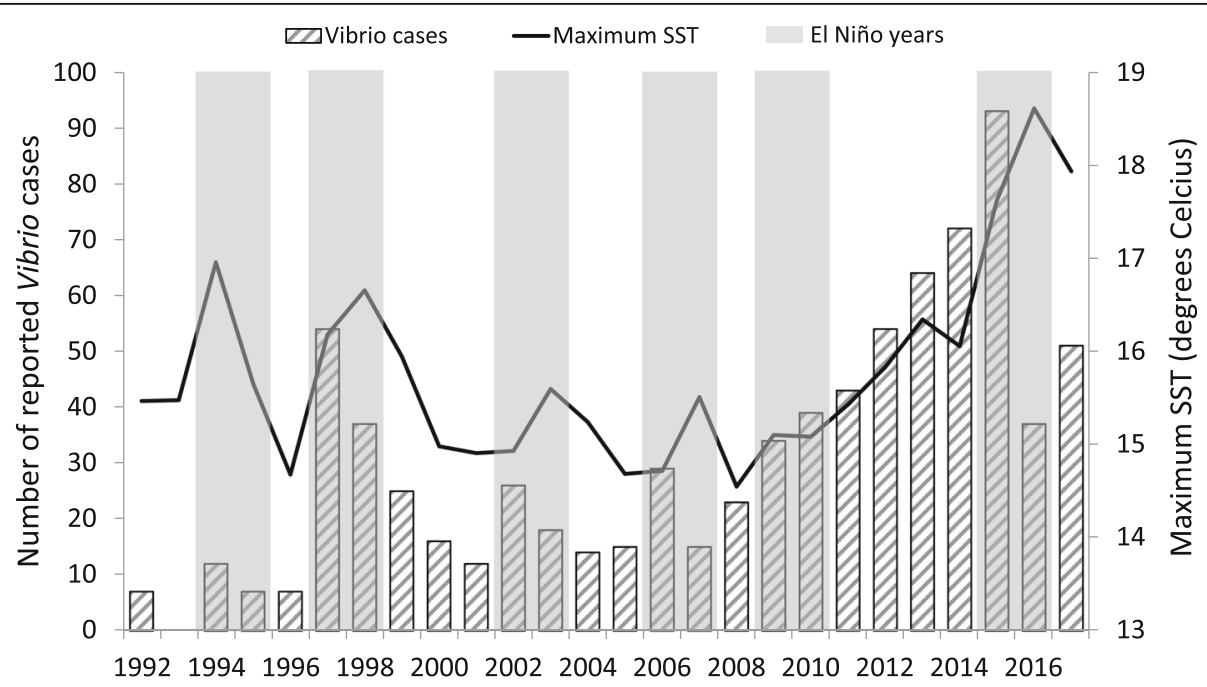

Fig. 1 Vibrio cases (all types) and yearly maximum sea surface temperature, British Columbia, Canada, 1992-2017. Years with moderate to strong E Niño Southern Oscillation (ENSO) events are shown with vertical grey bands (based on https://origin.cpc.ncep.noaa.gov/products/analysis_monitoring/ ensostuff/ONI_v5.php) 


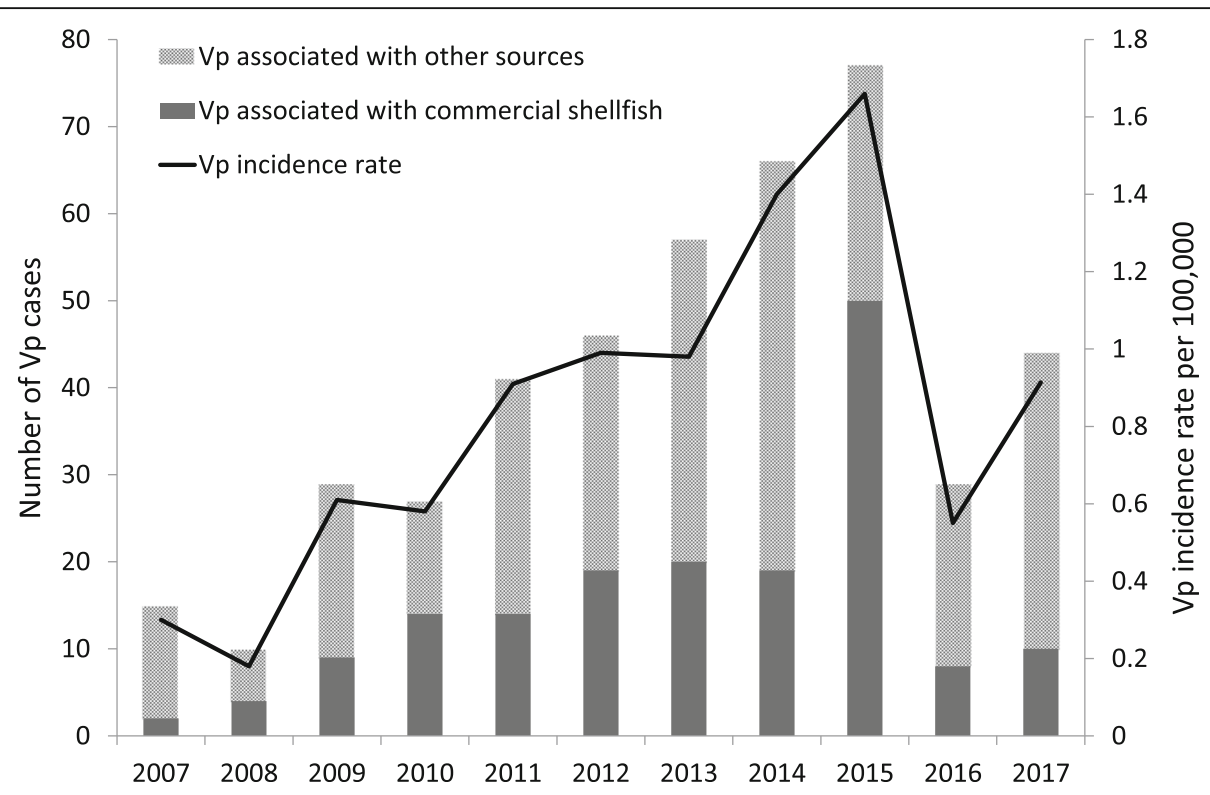

Fig. 2 Vibrio parahaemolyticus (Vp) cases and incidence rate, British Columbia, Canada, 2007-2017. Other sources include contact with water, travel and unknown source

with increasing numbers of Vibrio cases. Across 19922017, the correlation between annual Vibrio cases and maximum SST was significant $(r=0.46, P=0.018)$.

For Vibrio parahaemolyticus (Vp), the highest incidence rate was observed during the outbreak of 2015 at 1.7 cases $/ 100,000$ population (Fig. 2). This was mainly driven by an increase in cases associated with the consumption of commercially-harvested BC oysters, from
$35 \%(N=101 / 291)$ of $\mathrm{Vp}$ cases during 2007-2014 to $65 \%(N=50 / 77)$ in 2015 . Vp incidence dropped to $0.9 /$ 100,000 by 2017 , with an associated $81-84 \%$ drop in cases associated with commercial shellfish; indeed, only 8 and 10 reported cases were associated with commercial shellfish in 2016 and 2017, respectively.

Using sea and air temperature variables, our model captured observed seasonal variation in shellfish-

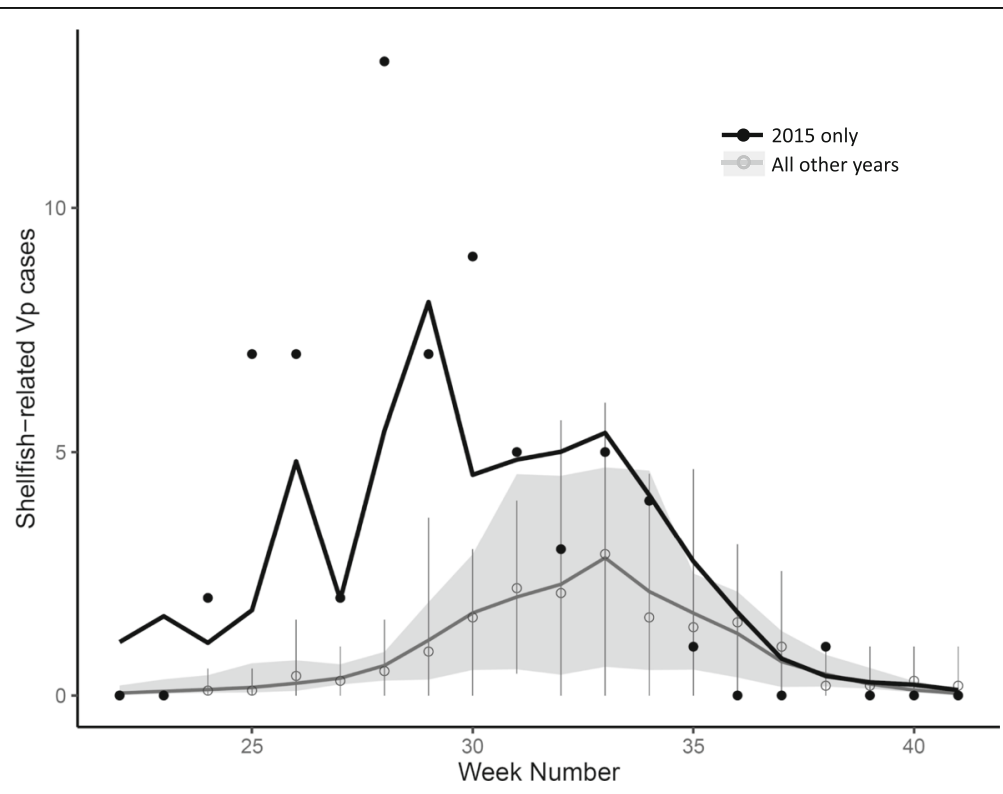

Fig. 3 Weekly observed and predicted shellfish-related Vp case counts, BC, 2007-2017. Filled circles represent observed case counts from the outbreak year 2015; open circles and bars represent the mean and 95\% Cls of observed case counts across non-outbreak years combined (20072014, 2016-2017). The black line shows the model fit for 2015; the grey line and shaded area show the median and minimum to maximum range of model fits for the non-outbreak years 
associated $\mathrm{Vp}$ in most study years, but notably underestimated the Vp outbreak of 2015 (Fig. 3). Whereas shellfish-associated Vp typically peaked during August (weeks 32-35), with average weekly counts of 2-3 cases, the 2015 outbreak peaked in early July (week 28) with up to 13 cases reported in a single week. Observed and model-predicted case counts differed by less than one case per week on average in non-outbreak years (mean \pm SD absolute weekly difference: $0.7 \pm 0.8$ cases), but differed by almost two cases per week during 2015 $(1.6 \pm 2.0$ cases). At the outbreak peak, the model underestimated the observed data by eight cases.

\section{Discussion}

Our study assessed trends in Vibrio parahaemolyticus $(\mathrm{Vp})$ incidence and associated measures of temperature in BC, Canada, before, during and after the 2015 Vp outbreak. The change in annual Vibrio cases during 19922017 was highly correlated with annual maximum sea surface temperature (SST), including the notable increase during 2008-2015. The peak Vibrio sp. incidences observed in 1997, 2002, 2006 and 2015 coincided with periods of elevated SST, reflecting El Niño Southern Oscillations or ENSO occurring in 1997-98, 2002-03, 2006 and 2015-2016 (https://www.esrl.noaa.gov/psd/enso/mei/). Our model based on SST and air temperature also explained the seasonal pattern of $\mathrm{Vp}$ incidence during most study years. Air temperature captures the oysters' exposure to potentially warmer air temperature found in intertidal oyster harvesting, during transport and at retail. However, the 2015 outbreak was not well explained by water and air temperature alone, with many more $\mathrm{Vp}$ cases reported than predicted.

Many studies have observed an increase in Vibrio sp. in association with warming temperatures globally. The frequency of detection of $\mathrm{Vp}$ and other Vibrio species has increased in bivalve shellfish on the Pacific and Atlantic coasts of Canada between 2006-9 and 2010-13 [14]. Increasing incidence of Vibrio illness has been noted in Europe and the US $[15,16]$. In the north Atlantic, the Northern Hemisphere Temperature warming and the Atlantic Multidecadal Oscillation are associated with increasing Vibrio present in the water in the last 50 years [17]. In the US, non-cholera Vibrio sp. increased from 1999 to 2014; incidence was associated with ENSO conditions and a more rapid increase in incidence was observed at higher latitudes [18].

We suggest that the 2015 outbreak in BC may in part have been associated with climatic factors known to have occurred in BC coastal waters, and in part with other factors such as the introduction of new Vp strains [19]. Climatic factors include the long-term increasing sea temperatures observed between 2008 and 2016, and may also have included the short-term temperature anomalies caused by the 2014-15 northern Pacific blob and the 2015-16 ENSO [9]. The rate of Vp illness can increase over many years in association with slowly increasing SST and large outbreaks can occur over a few months following short-term anomalies in SST [20]. During periods of climate anomalies, the usual relationship between Vp risk and SST may be disrupted; Martinez-Urtaza and colleagues found that during the 1997 El Nino, the risk of Vp infection in Peru was no longer associated with SST, but rather with sea height anomaly and heat content above $20 \mathrm{C}$, parameters that were not available in $\mathrm{BC}$ [21].

Beyond climatic factors, the introduction of new $\mathrm{Vp}$ strains into $\mathrm{BC}$ coastal waters may play a key role in $\mathrm{Vp}$ outbreaks. New strains may be imported through the discharge of ballast water from large ships during periods of warm weather, or through the introduction of warm water and invasive zooplankton transported from other regions [21, 22]. Various Vp strains circulate in the Pacific Northwest, including (ST)36, one of the most virulent strains $[23,24]$. Unfortunately, $\mathrm{Vp}$ isolates from 2015 were not available to assess strain variation.

The rapid drop in Vp incidence after the 2015 outbreak was mainly due to a decrease in cases associated with commercially-harvested shellfish. Following the outbreak, governmental, scientific and industry stakeholders in $\mathrm{BC}$ collaborated to identify gaps and implement actions to control $\mathrm{Vp}$ in commercial shellfish. These control measures may have contributed to the decrease in $\mathrm{Vp}$ incidence, as was also observed following the 1997 Pacific Northwest outbreak and the $2004 \mathrm{Al}$ aska outbreak [6, 22].

Washington (WA) State also reported increasing Vibrio sp. incidence between 2008 and 2014 (high of 1.3/ 100,000) [25]. In 2015, the WA Department of Health implemented a Vibrio Control Plan to determine the risk of shellfish growing areas and appropriate harvest requirements [26]. Although WA coastal waters were exposed to the same environmental conditions and presumably the same $\mathrm{Vp}$ strains as $\mathrm{BC}$, they did not experience an outbreak in 2015 (incidence of 1.0/100,000). This suggests that, although temperature is an important determinant of $\mathrm{Vp}$ growth, $\mathrm{Vp}$ may be controlled through mitigation measures such as those implemented for commercial shellfish in WA in 2015 and in BC in 2016.

This is an ecological study where changes in environmental factors were associated with population-level changes in $\mathrm{Vp}$ incidence. The observed changes in incidence cannot be directly attributed to a specific cause. We attempted to account for factors that could affect Vp incidence, namely SST, air temperature and product availability; however, we were limited by a lack of data for certain factors. Oyster consumption, for example, is 
not directly measured in BC. Instead, we used oyster production and oyster exports together as a proxy for oyster consumption. These data were available only at broader time scales (annual production, monthly exports) and it is likely that production varied during the year, particularly with increases during the summer. This may explain part of the seasonal increase in $\mathrm{Vp}$ incidence during 2015 and why our model underestimated the number of cases during the outbreak peak. We did not have reliable data on $\mathrm{Vp}$ in ocean water or in oysters. However, Konrad et al found that SST was an excellent predictor of the risk of $\mathrm{Vp}$ in oysters and of $\mathrm{Vp}$ illness in $\mathrm{BC}$ [5]. We considered other environmental parameters (e.g., ocean salinity and oxygen), but these were not consistently available in our study area for all study years. We did not have Vp strain data, given that typing was not routinely conducted during the study period.

\section{Conclusions}

Vibrio incidence was strongly related to sea surface temperature and, in our model, both sea and air temperatures were important predictors of $\mathrm{Vp}$ incidence in non-outbreak years. However, temperature did not fully explain the 2015 outbreak in BC and other factors may have contributed. Following the outbreak, control measures were implemented along the shellfish food chain which may have contributed to a decrease in Vp incidence while SST remained high. Vp subtyping would be useful in the future to understand the role of different strains in human illness, and the combined effects of changes in SST and strain emergence. Now that Vp incidence has decreased in $\mathrm{BC}$, it is essential to maintain control measures and ongoing awareness to avoid the increase in Vibrio illness that can occur with global warming.

\section{Acknowledgments}

The authors wish to acknowledge the laboratory professionals who diagnosed and reported Vibrio infections and the public health professionals who investigated the Vibrio cases.

\section{Authors' contributions}

EG conceived the study, interpreted the results and drafted the overall manuscript. MO designed and conducted the analyses and substantially revised the manuscript. MT acquired the data, interpreted the results and substantially revised the manuscript. All authors read and approved the final manuscript.

\section{Funding}

No external funding was received for this study.

\section{Availability of data and materials}

The environmental datasets analysed during the current study are available here:

- National Oceanic and Atmospheric Administration Optimum Interpolation Sea Surface Temperature (https://www.ncdc.noaa.gov/oisst)

- National Aeronautics and Space Administration satellite-based Multiscale UItrahigh Resolution product (https://podaac.jpl.nasa.gov/Multi-scale_Ultrahigh_Resolution_MUR-SST)
- Environment and Climate Change Canada (http://climate.weather.gc.ca/) The human illness datasets analysed during the current study are not publicly available due patient confidentiality concerns but are available for reasonable requests from the BC Centre for Disease Control through http:// www.bccdc.ca/about/accountability/data-access-requests.

\section{Ethics approval and consent to participate}

Ethics approval was not sought for this study as we used non-identifiable human data and the purpose was to improve understanding of epidemiological trends for public health purposes.

\section{Consent for publication}

Not applicable.

\section{Competing interests}

The authors declare that they have no competing interests.

Received: 29 January 2020 Accepted: 4 May 2020

Published online: 27 May 2020

\section{References}

1. Control of Communicable Diseases Manual. 20th ed. Heymann DL, editor. Washington DC: APHA; 2015.

2. Cook DW, Bowers JC, DePaola A. Density of Total and pathogenic (tdh+) Vibrio parahaemolyticus in Atlantic and Gulf Coast Molluscan shellfish at harvest. J Food Prot. 2002;65(12):1873-80.

3. Haley BJ, Kokashvili T, Tskshvediani A, Janelidze N, Mitaishvili N, Grim CJ. Molecular diversity and predictability of Vibrio parahaemolyticus along the Georgian coastal zone of the Black Sea. Front Microbiol. 2014;5:1-9.

4. Parveen S, Hettiarachchi KA, Bowers JC, Jones JL, Tamplin ML, McKay R. Seasonal distribution of total and pathogenic Vibrio parahaemolyticus in Chesapeake Bay oysters and waters. Int J Food Microbiol. 2008;128:354-61..

5. Konrad S, Padurao P, Romero-Barrios P, Henderson S, Galanis E. Remote sensing measurements of sea surface temperature as an indicator of Vibrio parahaemolyticus in oyster meat and human illnesses. Environ Health. 2017; 16(1):92.

6. Khaira G, Galanis E. Descriptive epidemiology of Vibrio parahaemolyticus and other Vibrio species infections in British Columbia: 2001-2006. Can Comm Dis Rep. 2007;33:12-22.

7. Gooch JA, DePaola A, Bowers J, Marshall DL. Growth and survival of Vibrio parahaemolyticus in postharvest American oysters. J Food Prot. 2002;65(6): 970-4.

8. BCCDC. Reportable Disease Dashboard. 2018 [cited 2018 Mar 16]. Available from: http://www.bccdc.ca/health-info/disease-system-statistics/reportabledisease-dashboard.

9. Taylor M, Cheng J, DSharma D, Bitzikos O, Gustafson R, Fyfe M, et al. Outbreak of Vibrio parahaemolyticus Associated with Consumption of Raw Oysters in Canada, 2015. Foodb Path Dis. 2018;15(9): 554-59.

10. Fyfe M, Yeung ST, Daly P, Schallie K, Kelly MT, Buchanan S. Outbreak of Vibrio Parahaemolyticus related to raw oysters in British Columbia. Can Comm Dis Rep. 1997;23(19):145-8.

11. Thomas MK, Murray R, Flockhart L, Pintar K, Pollari F, Fazil A, et al. Estimates of the burden of foodborne illness in Canada for 30 specified pathogens and unspecified agents, circa 2006. Food Pathog Dis. 2013;10(7):639-48.

12. BCCDC. Vibrio Infection Case Report Form. 2017 [cited 2018 March 16]. Available from: http://www.bccdc.ca/health-professionals/professionalresources/surveillance-forms.

13. Joinpoint Regression Program. Version 4.1.1 ed. Statistical Research and Applications Branch: National Cancer Institute; August 2014.

14. Banerjee SK, Rutley R, Bussey J. Diversity and dynamics of the canadian coastal vibrio community: an emerging trend detected in the temperate regions. J Bacteriol. 2018;200(15):200e00787-17.

15. Baker-Austin C, Trinanes JA, Taylor NGH, Hartnell R, Siitonen A, MartinezUrtaza J. Emerging Vibrio risk at high latitudes in response to ocean warming. Nat Clim Chang. 2013;13(1):73-77.

16. Newton A, Kendall M, Vugia DJ, Henao OL, Mahon BE. Increasing rates of vibriosis in the United States, 1996-2010: review of surveillance data from 2 systems. Clin Infect Dis. 2012;54(Suppl 5):S391-5.

17. Vezzulli L, Grande C, Reid PC, Helaouet P, Edwards M, Hofle MG, et al. Climate influence on Vibrio and associated human diseases during the past 
half-century in the coastal North Atlantic. Proc Natl Acad Sci U S A. 2016; 113(34):E5062-71.

18. Logar-Henderson C, Ling R, Tuite AR, Fisman DN. Effects of large-scale oceanic phenomena on non-cholera vibriosis incidence in the United States: implications for climate change. Epidemiol Infect. 2019;147:e243.

19. Government B. Change in Sea Surface Temperature in B.C. (1935-2014) 2017 [cited 2020 Mar 19]. Available from: http://www.env.gov.bc.ca/soe/ indicators/climate-change/sea-surface-temperature.html.

20. Martinez-Urtaza J, Bowers JC, Trinanes J, DePaola A. Climate anomalies and the increasing risk of Vibrio parahaemolyticus and Vibrio vulnificus illnesses. Food Res Int. 2010:43:1780-90.

21. Martinez-Urtaza J, Huapaya B, Gavilan RG, Blanco-Abad V, Ansede-Bermejo J, Cadarso-Suarez C. Emergence of Asiatic Vibrio diseases in South America in phase with El Nino. Epidemiology. 2008;19(6):829-37.

22. McLaughlin JB, DePaola A, Bopp CA, Martinek KA, Napolilli NP, Allison CG. Outbreak of Vibrio parahaemolyticus gastroenteritis associated with Alaskan oysters. N Engl J Med. 2005;353:1463-70.

23. Banerjee SK, Kearney AK, Nadon CA, Peterson CL, Tyler K, Bakouche L, et al. Phenotypic and genotypic characterization of Canadian clinical isolates of Vibrio parahaemolyticus collected from 2000 to 2009. J Clin Microbiol. 2014; 52:1081-8.

24. Martinez-Urtaza J, van Aerle R, Abanto M, Haendiges J, Myers RA, Trinanes J, et al. Genomic variation and evolution of Vibrio parahaemolyticus ST36 over the course of a transcontinental epidemic expansion. mBio. 2017:8(6):1-17.

25. WADOH. Washington State Communicable Disease Report 2016. 2017 [cited 2018 March 16]. Available from: https://www.doh.wa.gov/Portals/1/ Documents/5100/420-004-CDAnnualReport2016.pdf.

26. WADOH. Vibrio Control Plan Rule Requirements. 2015 [cited 2018 March 16]. Available from: https://www.doh.wa.gov/CommunityandEnvironment/ Shellfish/CommercialShellfish/NibrioControlPlan.

\section{Publisher's Note}

Springer Nature remains neutral with regard to jurisdictional claims in published maps and institutional affiliations.

Ready to submit your research? Choose BMC and benefit from:

- fast, convenient online submission

- thorough peer review by experienced researchers in your field

- rapid publication on acceptance

- support for research data, including large and complex data types

- gold Open Access which fosters wider collaboration and increased citations

- maximum visibility for your research: over $100 \mathrm{M}$ website views per year

At $\mathrm{BMC}$, research is always in progress.

Learn more biomedcentral.com/submissions 